\title{
DIVISÃO SEXUAL DO TRABALHO: A SEPARAÇÃO DA PRODUÇÃO DO ESPAÇO REPRODUTIVO DA FAMÍLIA
}

\author{
SEXUAL DIVISION OF LABOR: SEPARATING PRODUCTION FROM THE FAMILY'S \\ REPRODUCTIVE SPACE
}

\author{
Ana Elizabeth Santos Alves ${ }^{1}$
}

Resumo Este ensaio tem como objetivo central analisar a divisão sexual do trabalho em torno da dissociação do trabalho produtivo do espaço da reprodução familiar, ocorrida no processo de instalação e desenvolvimento do capitalismo no Brasil, particularmente com base em reflexões sobre o contexto histórico de finais do século XIX até meados do século XX. Nossa intenção é descaracterizar análises acerca da ideologia naturalista que legitima princípios de separação entre trabalhos de homens e trabalhos de mulheres. Para tanto, tratamos de explicar essa dissociação a partir de transformações na família como base produtiva, bem como da relação entre produção e reprodução na unidade rural (tradicional). Procuramos também relatar como ocorreram algumas transformações nas práticas de família tradicional, mediante a separação entre as atividades produtivas e o dia a dia do lar, o que contribuiu para a gênese da sociedade urbano-industrial, em face de uma consonância entre as unidades tradicionais com as unidades modernas de produção. Palavras-chave divisão sexual do trabalho; família; sociedade brasileira; capitalismo.
Abstract This essay aims at examining the sexual division of labor around the dissociation of productive work from the family reproduction space that took place during the installation and development of capitalism in Brazil, particularly based on reflections on the historical context between the late nineteenth century and the mid-twentieth century. This shows our intent to decharacterize analyses of the naturalistic ideology that legitimizes the principles of separation of the work of men and that of women. Therefore, we try to explain this dissociation based on changes that have taken place in the family as a productive base, as well as the relationship between production and reproduction in the rural unit (traditional). We will try to report how some of the changes took place in traditional family practices, by separating productive activities from everyday life at home. This confirmed the genesis of the urban-industrial society, in the face of consonance between traditional units and modern production units.

Keywords sexual division of labor; family; Brazilian society, capitalism. 


\section{Introdução}

Nas sociedades pré-industriais da Europa ocidental, o que caracterizava a vida das famílias era a integração entre as funções domésticas e o trabalho produtivo, realizados num único ambiente, no qual homens e mulheres desenvolviam atividades sexualmente diferenciadas, tanto nos serviços da casa como na produção. Hobsbawm (1988, p. 276) explica que os agricultores, os mestres-artesãos, os pequenos lojistas precisavam do trabalho das esposas para criar os filhos e ajudar nos negócios. As mulheres viviam presas a esse duplo trabalho e gozavam de uma condição de inferioridade e desigualdade em relação à posição social do homem, já evidenciando uma dada divisão sexual do trabalho.

As transformações das unidades de produção familiar despontam com o surgimento das indústrias domésticas, cuja produção já se dirigia para o mercado mais amplo. Na medida em que o trabalho era feito dentro de casa, combinado com o serviço doméstico, o lugar da mulher não se modifica; inclusive havia algumas manufaturas que produziam artigos femininos e ofereciam oportunidades de ganho para elas. A presença das indústrias domésticas contribuiu para modificar as diferenças estabelecidas entre o trabalho feminino e o masculino, a exemplo de comunidades de rendeiras - em que as mulheres permaneciam sentadas de doze a dezesseis horas por dia, enquanto os homens cultivavam as suas pequenas propriedades ou cuidavam dos rebanhos - e das manufaturas de algodão, que absorviam o trabalho industrial do casal como única fonte de rendimento da família (Hufton, 1991). Além disso, Hobsbawm (1988) lembra que essas transformações provocam também mudanças nas estratégias familiares, ao criar situações em que os filhos, logo que atingiam a idade de trabalhar, podiam formar novas famílias, constituindo seu próprio domicílio. Tal procedimento automaticamente deixava de adicionar força de trabalho ao grupo familiar e de certa forma interferia no mecanismo tradicional de manutenção das famílias do ponto de vista econômico e social, alterando a situação da mulher.

$\mathrm{O}$ avanço do desenvolvimento industrial descaracterizou o modelo de trabalho domiciliar como um empreendimento familiar, tornando-o um tipo de trabalho mal pago que explora a mão de obra feminina na casa. Lenin (1985), ao analisar o crescimento do capitalismo na Rússia, ressaltou as transformações da unidade de produção doméstica e artesanal para o assalariamento. No Brasil, um exemplo histórico do trabalho domiciliar é a atividade de costureira exercida por mulheres, serviço encomendado pelas indústrias de sacaria de juta do século XIX, cuja remuneração era importante para prover o sustento da família (Matos, 2002).

Ao lado dessa realidade, um segundo efeito no avanço do processo de industrialização provocou um deslocamento de um contingente de homens 
e mulheres para trabalhar na fábrica, separando a casa do local de trabalho. Ressalta-se que esse movimento não superou a coexistência de outras formas de trabalho preexistentes, especialmente nas unidades de produção familiar rural. O resultado dessas transformações trouxe consequências para a divisão sexual do trabalho.

$\mathrm{O}$ artigo tem como objetivo central analisar a divisão sexual do trabalho em torno da dissociação do trabalho produtivo do espaço da reprodução, ocorrida no processo de instalação e desenvolvimento do capitalismo na sociedade brasileira, particularmente com base em reflexões sobre contexto histórico de finais do século XIX até meados do século XX. Procura-se contribuir para análises mais críticas acerca da ideologia naturalista que legitima princípios de separação entre trabalhos de homens e trabalhos de mulheres, sintetizando essas separações mediante argumentos naturais e descaracterizando a natureza desigual e hierárquica dessa separação. Para tanto, tratamos de explicar essa dissociação a partir das transformações da família como base produtiva, da relação entre produção e reprodução e do conceito de unidade de produção rural (tradicional), ao mesmo tempo que relatamos como aconteceram mudanças na família tradicional, de forma a acompanhar as ocorrências do movimento de separação entre as atividades produtivas e o dia a dia do lar. Tais mudanças representaram a gênese da modernização da sociedade urbano-industrial e o nascimento das unidades modernas de produção, coexistindo com as unidades tradicionais de produção doméstica.

\section{Breves considerações em torno do conceito de divisão sexual do trabalho}

As discussões acerca da divisão sexual do trabalho no campo das ciências sociais e também do ponto de vista histórico foram direcionadas, durante muito tempo, a uma perspectiva fundamentada em papéis atribuídos de acordo com o sexo. Kergoat (1992 apud Hirata, 2002, p. 275-277) e Hirata (2002) desmistificam essa ideia, delineando um novo olhar a respeito do trabalho. As autoras observam que o conceito de trabalho deve ser ampliado, incluindo o trabalho doméstico, 2 o trabalho não remunerado e o trabalho informal. A inclusão desses elementos permite evidenciar uma massa de trabalho invisível, realizado por mulheres, no conceito de trabalho, nos chamando a atenção para a sua dimensão sexuada. Kergoat (1992, p. 16 apud Hirata, 2002, p. 275) vincula as relações sociais entre os sexos e a divisão social e sexual do trabalho como "duas expressões indissociáveis".

As análises a respeito das relações sociais de sexo e as relações de classe sempre foram compreendidas de forma antagônica. As primeiras (relações sociais de sexo) são entendidas como "desiguais, hierarquizadas, assimétricas ou antagônicas de exploração e de opressão entre duas categorias de sexo 
socialmente construídas" (Hirata, 2002, p. 276); as segundas (relações de classe), como um dos componentes da superexploração econômica de homens e de mulheres no trabalho e na sociedade. Ou seja, as expressões "relações de classe ou relações de sexo, antagonismos de classe ou antagonismos de sexo"( Hirata, 2002, p. 276) eram sempre estudadas de forma separada e segundo critérios de importância entre elas. A 'nova' abordagem busca contextualizar de modo inseparável, indissociável, as relações sociais de sexo e de classe, permitindo "reconceitualizar o trabalho, dinamizá-lo, a partir da introdução de uma subjetividade efetiva, ao mesmo tempo 'sexuada' e de 'classe', de acordo com a expressão de Kergoat" (Hirata, 2002, p. 277). Nesse sentido, podemos compreender de modo mais claro o conceito de divisão sexual do trabalho.

A divisão sexual do trabalho, mediada por situações historicamente dadas entre pessoas de sexo oposto, fundamenta-se na ideia da relação antagônica entre homens e mulheres, mas também nas relações de exploração que sofrem os sexos. A "divisão social e técnica do trabalho é acompanhada de uma hierarquia clara do ponto de vista das relações sexuadas de poder" (Hirata, 2002, p. 280). Uma das suas principais características está na destinação primeira, que é situar os homens no campo produtivo e as mulheres no campo reprodutivo, associando aos primeiros as funções com forte valor social, como na esfera política, religiosa e militar. Além disso, baseia-se em dois pressupostos organizadores, o da 'separação', que distingue trabalhos de homens e trabalhos de mulheres, e o da 'hierarquização', que indica ser maior o valor do trabalho de homens (Kergoat, 2009, p. 67).

A definição dos espaços entre produção e reprodução, ${ }^{3}$ público e privado 4 vivenciados pelos sexos (ou também podemos dizer pelos agentes familiares) remete a diferentes formações sociais. No mundo grego, por exemplo, a divisão social do trabalho e a divisão sexual do trabalho já evidenciavam as desigualdades nas relações sociais entre os homens: a exploração do homem pelo próprio homem e a exploração de gênero. Aos homens livres, era reservada a vida pública, a responsabilidade pelas decisões sobre a vida da cidade. No mundo medieval, o trabalho fazia parte da vida das famílias, pois não se separava o lugar onde as pessoas moravam do lugar do ócio e dos atos sociais dessas pessoas. A mulher camponesa era ligada ao marido no seu trabalho como artífice ou pequeno comerciante; eles eram unidos por interesses únicos. Entretanto, o espaço da unidade familiar não era homogêneo, uma vez que apresentava diferenciações nas relações entre os sexos, entre espaço público e espaço privado. O marido era o responsável pela mulher, que não tinha quase nenhuma relação direta autônoma com o poder público nem com indivíduos estranhos à família (Opitz, 1990).

No capitalismo, a separação entre os sexos nos espaços e tempos de produção e reprodução se expandiu. As mulheres prioritariamente foram desig- 
nadas para o lugar da reprodução, e os homens para a produção. Entretanto, podemos considerar que essa separação não acontece de forma indiscriminada, tendo em vista a presença de mulheres na produção e homens na reprodução, "quaisquer que sejam as modalidades dos papéis ocupados e os modos de produção". Além disso, é importante considerar que se faz presente "uma única divisão sexual do trabalho operando na produção e na reprodução, materializando sempre, em ambos os aspectos, a subordinação de um sexo ao outro" (Combe e Haicault,1986, p. 26).

\section{A família brasileira}

A formação social brasileira demonstra diferentes padrões de estrutura familiar, em razão do tempo, do espaço e dos grupos sociais. Compreendemos, conforme explicitou Corrêa (1994), que não há um tipo universal de família brasileira (ou uma visão universalista) como modelo único e estático, mas a compreensão da categoria família em uma processualidade histórica (Silveira, 2006). Nessa perspectiva, podemos pensá-la articulada ao projeto de produção/reprodução e à estrutura de classes sociais e de sexo, considerando o seu significado numa dimensão diacrônica e sincrônica, levando em conta a necessidade de olhar a "contribuição invisível das mulheres para a vida econômica e a divisão sexual do trabalho que as afeta prioritariamente na esfera da reprodução" (Devereux, 2009, p. 98).

Pesquisas baseadas em estudos históricos (Corrêa, 1994; Samara, 1989) chamaram a atenção para a coexistência de várias formas de organização familiar e a dificuldade em discorrer sobre cada uma delas. Um dos pontos principais dessas análises partiu da crítica à descrição de família baseada nos estudos de Gilberto Freyre (1963; 1961). O autor pesquisou as regiões dos engenhos de cana-de-açúcar, as fazendas de gado e de café e caracterizou de modo homogêneo o conjunto da família brasileira no século XVIII como família patriarcal; e, por conseguinte, de modo linear, a partir do desenvolvimento da urbanização e da industrialização no século XIX e início do século XX em família moderna. Esse olhar homogêneo a respeito da organização da família brasileira condiciona pensarmos a sua estrutura segundo os padrões dominantes, não levando em conta as variações, os conflitos, resistências e diferentes valores morais. Diante do exposto, segundo nossa compreensão, as bases históricas para pensarmos sobre o movimento de separação do trabalho produtivo do espaço da reprodução, ocorrido no processo de industrialização (transição para uma ordem capitalista), aliado à transformação da família e das unidades de produção rural, giram em torno da concepção de família tradicional e moderna, tendo em vista a dinâmica processual entre permanências e mudanças das estratégias familiares na luta pela sobrevivência. 
A constituição da família tradicional (patriarcal) brasileira iniciou-se com a solidificação da base econômica e legal da Colônia, com o direito canônico e o respaldo da Igreja Católica, ligada ao latifúndio e à escravidão. A organização dessa família herdou traços da herança cultural portuguesa fundamentada no direito paterno, no poder patriarcal, centrado na ideia do homem como chefe de família e na submissão e reclusão da mulher. A Igreja metropolitana, a serviço do Estado português, buscava controlar as populações coloniais, ditando regras morais, principalmente em relação às mulheres. "A igreja entendia que confinada à casa, delimitada pela privacidade doméstica, a mulher, e sobretudo a mãe, poderia fazer o trabalho de base para o estabelecimento do edifício familiar" (Del Priore, 1994, p. 69).

A família tradicional, formada segundo padrões patriarcais e valores tradicionais, era unidade de produção e reprodução; concentrava as funções econômico-sociais e desempenhou uma função importante na sociedade colonial. Essa prática de família pré-industrial, de caráter exclusivamente rural, do ponto de vista dos papéis sociais em geral, era organizada em torno do marido e pai, ao qual se subordinavam as mulheres, os filhos, parentes e agregados. No entanto, a prática de família nuclear não pode ser retratada de modo exclusivista nesse período colonial brasileiro, porque muitas vezes os lares eram formados e chefiados por mulheres. A casa-grande representava o espaço de organização do núcleo doméstico no qual se dirigia a vida social, política e econômica de uma 'família extensa'.

O povoamento do Brasil Colônia, nas relações entre homens e mulheres, na formação das famílias, oportunamente seguiu uma lógica avessa às regras da família tradicional, ancorada nos ideários da Igreja Católica. O exemplo são as famílias consensuais na Bahia, relatadas por Mattoso (1992), fundadas no consentimento mútuo dos parceiros e não reconhecidas pela Igreja. Havia famílias formadas por "maridos ausentes, companheiros ambulantes, mulheres chefiando seus lares e crianças circulando entre outras casas e sendo criadas por comadres, vizinhas e familiares." (Mattoso, 1992, p. 142-143).

O fato de a sociedade ser estratificada do ponto de vista legal e racial, entre brancos, negros e índios, no espaço urbano e rural, facilitou a formação de diferentes padrões de organização familiar. Nas plantações de cana-de-açúcar ou de café, a unidade de produção era formada por um grupo de parentela, acrescido pela presença dos dependentes e escravos, compondo a base da família patriarcal. "A 'grande família', hipertrofiada e multifuncional, englobava todos numa mesma unidade econômica, 'centro e núcleo da vida social', 'força social que se desdobrava em força política', verdadeira 'aristocracia rural'" (Mattoso, 1992, p. 142-143). Havia também, segundo essa autora, famílias livres ou escravas em diversos tipos de associações familiares que agregavam parentes ou amigos pobres, ou então escravos alforriados, tipos presentes tanto no campo como nas cidades, mantendo 
relações de dependência e subordinação em relação ao chefe das famílias que os haviam recebido. Mattoso mostra que não só existiam relações familiares entre senhores brancos e escravos negros, mas também famílias formadas por pessoas livres alforriadas ou escravas. Uma sociedade rural na qual o campesinato sempre esteve presente.

Em Minas Gerais, conforme Cardoso (1996), pesquisas mostram que no auge da mineração também existia uma estrutura agrária diversificada de alimentos de produção camponesa formada por famílias, ao lado da escravista.

Nos municípios cafeeiros do Rio de Janeiro, no século XIX, encontravam-se diferentes grupos sociais formados por 'homens livres e pobres' como pequenos produtores de alimentos e pequenos comerciantes em unidades de produção familiar (unidades camponesas), interagindo com o mercado em uma lógica diversa daquela escravista-mercantil (Fragoso, 1996).

O viajante Saint-Hilaire, em uma das suas visitas pelo Brasil (século XIX), relata a passagem em uma casa de camponeses, provavelmente um pequeno sítio, e descreve a situação da mulher dentro da família. Segundo o autor, logo que chegou à casa foi recebido por "uma mulata vestida de saia e camisa de algodão muito sujos", rodeada por uma "grande quantidade de bonitas crianças, trajadas do modo mais pobre" (Saint-Hilaire, 1974, p. 34), cujo marido e cujo filho estavam caçando no mato. A mulher ocupava-se o dia inteiro dos trabalhos caseiros, dos animais domésticos, das plantações e da colheita.

A família brasileira, isolada dos núcleos urbanos, teve por muitos séculos o monopólio de suas práticas fixadas no meio rural. O espaço familiar, além de servir de centro para os relacionamentos sexuais, a reprodução do grupo, cuidados com os filhos e a alimentação, assumia a função de unidade produtiva. ${ }^{5}$

Após a abolição da escravatura tanto no Sudeste como no Centro-Oeste e no Nordeste, apesar das diferenças inter e intrarregionais, assistiu-se à passagem da agricultura de agroexportação para diversos tipos de relações não capitalistas de produção, como parceria, colonato, morador, tendo por base o trabalho familiar (plantação de roças de subsistência) e a continuação do controle sobre a terra nas mãos dos fazendeiros, que faziam uso da mão de obra não remunerada de mulheres e crianças. Na Bahia, muitos escravos continuaram morando nas fazendas sob um novo regime de trabalho: exerciam quatro dias de atividade por semana para os patrões e três dias no seu roçado (Mattoso, 1992).

Do ponto de vista econômico e cultural, é esclarecedora a descrição de Cândido (1972) em relação à região de São Paulo. Segundo esse autor, as grandes propriedades de cana, gado e café foram adquiridas por meio de compra ou espoliação, à custa de proprietários menores, e eram movidas pela mão de obra servil e agregados dependentes de favores. As fazendas funcionavam como unidades produtivas ligadas às atividades de troca - vendendo e comprando produtos e, desse modo, interagindo com o mercado. O trabalho 
compulsório interferia na organização familiar, nas vivências do dia a dia, gerando uma atitude que identificava o trabalho com a servidão e o lazer com a dominação.

Os proprietários de pequenos pedaços de terra e lavradores sitiantes, que na maioria das vezes detinham a posse da terra de modo irregular pela precariedade dos direitos, cultivavam lavouras de subsistência com níveis mínimos de sobrevivência, mas dependiam dos latifúndios para prosseguir na sua faina. Abrigavam em suas casas uma pequena indústria doméstica que, com o apoio do trabalho familiar, era responsável pelo fabrico de bens de consumo, como os utensílios e as roupas, e pela manipulação de gêneros alimentares - o que contribuía notavelmente para a autossuficiência da família. Essa organização constituiu-se na gênese do campesinato brasileiro, já que a produção de alimentos se fazia no âmbito do trabalho familiar, quer no interior do latifúndio agroexportador, quer na sua periferia por meio do lavrador dependente, com envolvimento de homens, mulheres e crianças.

A definição do espaço de trabalho concomitante à vida privada da família e as suas relações com o resto da sociedade, assim como a definição do modo moderno separando o lar, a família, a vida privada da família da esfera pública, são realidades históricas construídas de diferentes formas pela organização social. As linhas divisórias entre o público e o privado nem sempre existiram, lembra Perrot (1988). Cada formação social imprime o modo próprio na definição dos momentos em que as atividades familiares de produção e reprodução (vida privada da família e vida pública) se mesclam e outros modos em que esses momentos estão explicitamente diferenciados.

Por exemplo, Prost (1992) relata casos da França do início do século XX em que, para várias famílias de classes populares, o trabalho e a vida privada eram totalmente integrados, e os espaços se mesclavam como no exemplo de costureiras domiciliares, em que a mesa era usada tanto para as refeições como para o corte dos tecidos e para a realização de tarefas pelos filhos. Era nesse mesmo espaço que elas recebiam os fregueses para tirar medidas, experimentar roupas e fazer pagamentos. O autor sugere ainda que, para muitos camponeses, comerciantes e artesãos, a família constituía uma unidade de produção autônoma, uma célula econômica.

Nas cidades no Brasil, o trabalho em domicílio, remunerado, exercido no cotidiano invisível das donas de casa, como costureiras ou doceiras, foi objeto de diversas pesquisas, como nos lembram Abreu e Sorj (1993). ${ }^{6}$

Matos (2002) estuda o desenvolvimento do trabalho fabril nas cidades de Santos e São Paulo, entre 1890 e 1930, e destaca a importante contribuição das oficinas domiciliares para as indústrias de sacaria de café, sendo o universo de artesãos dessas unidades na sua maioria composto por mulheres.

No trabalho de produção no campo, é comum o envolvimento de toda a família, inclusive crianças e velhos, destacando-se também a importância 
econômica do trabalho da mulher para a família. As fazendas eram centro de produção, reprodução e consumo, como nos relata a memorialista Galvão (1988) sobre a sua infância no campo na Bahia (década de 1920), na Mesorregião Centro-Sul Baiano, ao lembrar-se da propriedade como um lugar de moradia e também de espaço de sustento da família. A autora narra que o seu avô e, posteriormente, o seu pai eram fazendeiros, donos de grandes extensões de terras. Viviam em casas rodeadas de varandas e de escravos que passaram, após a abolição, a ser agregados, ou de moradores vizinhos que receberam um 'cantinho de terra' doado pelo avô para fazer um rancho ou, ainda, trabalhadores que viviam na miséria e sempre estavam prestando serviços nas roças e nas cozinhas da casa-grande em troca de 'algum pagamento' ou de favores (a exemplo de remédios). O pai, o chefe da família (o patrão), era político e negociante de gado, de cereais e de cavalos. As mercadorias eram levadas por tropas para serem negociadas em outras regiões, guiadas por vaqueiros empregados, e geralmente o filho ou alguém de confiança do fazendeiro efetuava o negócio. Desse modo, os fazendeiros interagiam com o mercado. Nessas viagens, os filhos dos fazendeiros conheciam as futuras esposas e formavam novas famílias (Galvão, 1988).

Na virada do século XIX para o XX, no Brasil, a economia apresentava uma precária divisão social do trabalho e uma circulação limitada de mercadorias (baixos índices de mercantilização). No entanto, já se observam o crescimento da população urbana, os primeiros passos da industrialização, com a formação de capital industrial e da classe operária, e também as transformações na organização das famílias nas cidades.

As mudanças sociais originadas do novo sistema de valores, criado pelo modo de civilização urbano-industrial, produziram alterações nas estratégias de organização da família, principalmente em cidades mais desenvolvidas, como São Paulo. Os novos tipos são coincidentes com a formação "da família da classe média, do meio operário e dos novos núcleos subproletários como o mocambo e a favela resultantes da imigração da mão-de-obra do campo para a cidade" (Miranda Netto et al., 1986, p. 462), enquanto na maioria das cidades do interior o funcionamento das práticas tradicionais de família ainda é uma realidade.

O declínio das unidades de produção tradicional rural (unidades domésticas) 7 e a ascensão das unidades de produção moderna (indústrias) podem ser compreendidos, do ponto de vista histórico, pelo movimento de mesclagem entre o espaço de trabalho familiar tradicional com o espaço público, associado à transformação da família, marcando as transformações dos espaços de trabalho no início do século XX, como adverte Prost:

Trata-se de um duplo movimento. Em primeiro lugar, um movimento de separação e especialização dos espaços: os locais de trabalho já não são mais os da vida doméstica. 
Mas essa diferenciação dos locais vem acompanhada por uma diferenciação das normas: o universo doméstico se liberta de regras anteriormente ligadas ao trabalho que ali se realizava, ao passo que o mundo do trabalho passa a ser regido não mais por normas de ordem privada, e sim por contratos coletivos (Prost, 1992, p. 21).

A questão central a ser destacada nesse contexto, para pensarmos o Brasil no início do século XX, pode ser compreendida por meio de reflexões sobre o avanço das relações capitalistas na vida privada das famílias, regulando a maneira de morar, a saúde, a educação e a sexualidade. A ideia central era integrar os(as) trabalhadores(as) ao universo dos valores burgueses e intensificar a separação entre o trabalhador e a sua força de trabalho, tendo em vista formar a classe operária para o mercado de trabalho. Para tanto, forjam-se novos costumes que devem ser seguidos por mulheres e homens no sentido de "erradicar práticas e hábitos considerados perniciosos e tradicionais", redefinindo as práticas de família (Rago, 1997, p. 12). Assim, podemos observar a determinação de um modelo ideal de família no qual reafirmava-se o espaço privado, doméstico, como natural às mulheres, determinado pelas necessidades da maternidade e realização das capacidades de trabalho femininas, somado a um discurso médico que procurava nas diferenças biológicas comprovar que a mulher era mais frágil e inferior em relação ao homem.

\section{Capitalismo, divisão sexual do trabalho e família no Brasil}

O rompimento do estatuto colonial no Brasil, na virada do século XIX para o XX, coaduna a desagregação do regime servil e da sociedade estamental, originando novas estruturas econômicas pela expansão do sistema capitalista. É um momento caracterizado pela constituição do processo de industrialização, originando novas estruturas sociais e econômicas ao lado da instalação e ampliação das estradas de ferro, do crescimento dos centros urbanos e das atividades econômicas próprias das cidades. Entretanto, a agricultura continuava sendo o principal setor da economia, uma vez que em 1920 ela ainda ocupava $66,7 \%$ da população ativa, baseada no trabalho livre (Fragoso, 1996).

O desenvolvimento das cidades e o crescimento do comércio abriram espaço para a expansão de uma rede de mercantilização da produção interna e a formação de uma rede de serviços, ligada à organização do Estado nacional. Os fazendeiros de café do sul do país e os senhores de engenho saem do isolamento do campo e se projetam no cenário econômico das cidades. Formam uma 'nova' força social dominante com ideias, concepções políticas e aspirações sociais segundo uma mentalidade capitalista. Desse estrato, 
surgem os negociantes de varejo e por atacado, os funcionários públicos, os banqueiros e os empresários das indústrias nascentes de bens de consumo, que se juntam às figuras de outros agentes sociais, o trabalhador livre e o imigrante, inaugurando a nova ordem econômica, política, social e cultural para a implantação do regime republicano. Os fazendeiros de café contribuíram para a formação da nova classe de comerciantes e do ramo ligado à indústria. Aos poucos, a vida nas cidades passa de um simples prolongamento do meio rural para um estilo urbano-industrial (Fernandes, 1973).

A formação do proletariado industrial nasceu das atividades de trabalho artesanal e industrial que despontaram com a expansão dos polos urbanos, comerciais e industriais. O desenvolvimento das cidades demandou uma crescente especialização de funções, ocasionando a ampliação da divisão social do trabalho. Para atender à necessidade de mão de obra, introduziu-se a força de trabalho do imigrante europeu, com formação diferenciada dos quadros da produção escravista. Essa nova realidade contribuiu para transformar as relações de trabalho da sociedade tradicional rural, desencadeando o movimento operário e as exigências de novos padrões de comportamento nas relações entre proprietário e trabalhador.

O regime de trabalho livre envolvia tanto as relações de produção capitalistas como as não capitalistas. Por exemplo: no campo, a prática do colonato era uma das formas de remuneração da força de trabalho não assalariada, uma vez que a remuneração paga pelo trabalho realizado era para a família. Entretanto, persistia a lógica da organização do trabalho capitalista na determinação do tempo de trabalho, local, horário, ritmo e controle exercido pelo patrão.

O final do século XIX marca a constituição de espaços distintos: o privado e o público, excluindo as mulheres deste último. O discurso que vigorava na época na França e que provocava reflexos também no Brasil apoiava-se nas pesquisas da medicina e da biologia que comprovavam a existência de duas espécies com qualidades e aptidões particulares: “aos homens o cérebro (muito mais importante do que o falo), a inteligência, a razão lúcida, a capacidade de decisão; às mulheres, o coração, a sensibilidade, os sentimentos" (Perrot, 1988, p. 177). Essas ideias definem a racionalidade harmoniosa da divisão sexual do trabalho, atribuindo para cada um dos sexos tarefas e espaços específicos, apoiados no discurso ideológico de ofícios que fazem "da linguagem do trabalho uma das mais sexuadas": "ao homem, a madeira e os metais, à mulher, a família e os tecidos" (Perrot, 1988, p. 178). O modo de produção capitalista reforça essa ideologia quando estabelece esta separação: da produção, incumbe-se somente o homem; da reprodução, há cooperação de ambos os sexos; e o consumo é o espaço que pertence às mulheres. O domínio das mulheres é o espaço doméstico e o da 'dona de casa', a responsável por cuidar dos filhos e gerir a economia doméstica, denominação imposta tanto para a mulher burguesa como para a operária. 
No contexto apresentado da sociedade capitalista, vale observar que a divisão sexual do trabalho é um elemento da divisão do trabalho. O novo modo de vida capitalista e a separação entre campo e cidade deram origem a uma nova divisão do trabalho e, consequentemente, à divisão sexual do trabalho, principalmente no que diz respeito à separação do espaço de produção do espaço do lar.

As mulheres das classes populares foram convocadas a trabalhar nas manufaturas e, mais tarde, nas indústrias, onde a força de trabalho feminina era reconhecida, por empregadores, como fonte de mão de obra barata, pouco produtiva, adequada para determinados tipos de trabalho e considerada como um fenômeno social segundo os modos de ser da natureza feminina (Hobsbawm, 2002).

Essas ideias marcam uma linha divisória entre a força de trabalho feminina e a masculina na sociedade burguesa, pois, pondera-se, há trabalhos que são considerados de homem e trabalhos de mulher. Que razões elucidam tal divisão? As explicações, segundo Scott (1991), partem dos argumentos que tratam da transferência do trabalho produtivo do lar para a fábrica durante o processo de industrialização, entre maternidade e salário, entre feminilidade e produtividade.

A mudança da produção do ambiente familiar para a manufatura e daí para a grande indústria, separando o lar do trabalho, foi usada por reformadores médicos, estatísticos, legisladores e cientistas para levantar questões políticas e morais sobre a 'mulher trabalhadora'. O que estava em jogo naquele momento era encontrar respostas para os questionamentos sobre o trabalho da mulher fora de casa e o tipo de trabalho que seria mais adequado a ela, demarcando a diversidade entre homens e mulheres no que diz respeito à formação, à capacidade de trabalho, a diferenças biológicas e funcionais. A resposta para essas questões construiu um discurso articulado com o novo modo de vida capitalista, fomentando a criação de uma força de trabalho feminina apta a exercer determinados tipos de ofícios.

Saffioti acrescenta que a sociedade capitalista estabelece certos tipos de trabalho feminino para determinados períodos, sempre com ocupações de reduzido prestígio. Mesmo que as atividades tradicionalmente exercidas por mulheres possam ser desenvolvidas "por outras categorias sociais subprivilegiadas, a sociedade necessita do trabalho das mulheres cujos rendimentos são imprescindíveis para sua sobrevivência" (Saffioti, 1979, p. 38) e manutenção da própria sociedade. A autora lembra ainda que a tradição de inferioridade, de subordinação e de desvalorização do trabalho da qual tem sido vítima historicamente a mulher contribuiu para a sua marginalização nas funções produtivas, educando-a de modo submisso para que o capitalismo extraísse o máximo de trabalho excedente. 
Ainda no século XIX, nos Estados Unidos, por exemplo, houve transferência de pessoas com ocupações domésticas urbanas e rurais para vagas que surgiram no setor de serviços (empregos de colarinho-branco), em escritórios, como secretárias, datilógrafas, e em escolas, proporcionando novas oportunidades de trabalho para as mulheres da classe média. Esses tipos de atividades eram associados a 'trabalho de mulher'. O fato de mulheres de classe média saírem de casa para trabalhar incomodou ideólogos reformadores em razão das possibilidades de casamento e da independência financeira que, porventura, poderia ser conquistada por essas mulheres. Nesse sentido, eles passaram a afirmar que a ausência do lar poderia comprometer as "competências domésticas da mulher" e atrapalhar suas "responsabilidades reprodutoras" (Scott, 1991, p. 452), generalizando os argumentos para o gênero feminino em geral. Essas alegações ajudaram a reservar às mulheres os empregos marginais e mal pagos.

No Brasil, essa realidade não é muito diferente. Pesquisas relatam o encaminhamento do modelo de família segundo os ideais burgueses que buscavam moldar a mulher para ser boa esposa e dona de casa, principalmente para as moças das famílias abastadas. Para as mulheres da classe trabalhadora, esse modelo é manipulado por uma representação simbólica de esposa e dona de casa, uma vez que o trabalho remunerado é essencial para ajudar na sobrevivência da família. A saída das mulheres para atuar em fábricas, escritórios e comércio é marcada por uma série de tabus e estratégias "masculinas, acordos tácitos, segredos não confessados que tentam impedir a livre circulação delas nos espaços públicos ou a assimilação de práticas que o imaginário burguês situou nas fronteiras entre a liberdade e a interdição" (Rago, 1997, p. 63). Assim, não se abrem horizontes profissionais para elas, pois a educação em geral visa prepará-las para a carreira doméstica. Os próprios homens da classe trabalhadora confabulam no sentido de direcionar as mulheres "à esfera privada da vida doméstica" (Rago, 1997, p. 64). Por exemplo, o estudo realizado por Chalhoub (2001, p. 204) no Rio de Janeiro, nos anos 1920, mostra que as atividades de ganho desenvolvidas por mulheres pobres, em geral, eram uma extensão das suas funções domésticas como lavadeiras, cozinheiras, engomadeiras. Muitas ainda se dedicavam a fabricar doces e salgados para vender na rua com a ajuda dos filhos.

Nas fábricas têxteis, ramo onde era grande a participação feminina, o leque de funções exercidas para os homens era muito maior; para elas, vários tipos de trabalho eram vedados, principalmente os cargos de chefia (Rago, 1997).

O trabalho para o qual as mulheres eram contratadas era considerado 'trabalho de mulher', dito como apropriado às suas capacidades físicas e produtivas, determinando sempre a elas as funções mais baixas na hierarquia ocupacional e menores salários. Os homens, por sua vez, observavam a 
entrada de mulheres no mercado de trabalho como uma ameaça para a diminuição dos seus salários. Entretanto, vale esclarecer, conforme Safiotti, que o salário pago pelos empregadores tanto para homens como para mulheres “não representa o valor criado pelo produtor imediato e que muitas vezes não chega mesmo a corresponder às necessidades de produção e reprodução da vida do trabalhador" (Safiotti, 1979, p. 39).

Alguns princípios são usados para legitimar a divisão sexual do trabalho. Em relação aos baixos salários recebidos pelas mulheres, as interpretações históricas dominantes justificam o fato de os ganhos recebidos pelos homens serem calculados de modo a garantir a sua sobrevivência e a reprodução da família. Os salários das mulheres seriam definidos como ganhos suplementares ao salário do homem, suficientes para o seu próprio sustento e o da família. O trabalho doméstico não era levado em conta nas discussões a respeito da reprodução das futuras gerações; consequentemente, era difícil para elas conseguirem ganhar a vida sozinhas ou produzir algum valor econômico expressivo. Contavam também para diminuir os salários das mulheres os argumentos de que elas eram menos produtivas do que os homens, pois não trabalhavam tão arduamente quanto eles; além do mais, o que produziam importava um menor valor econômico.

No que diz respeito ao movimento de separação da produção do ambiente familiar brasileiro na cafeicultura e na agroindústria açucareira, as explicações de Ianni (2004) ilustram como no início do século XX o mundo social era essencialmente rural. Os colonos na cultura do café gerenciavam as suas vidas sociais de acordo com o curso do desenvolvimento do capital agrário. Envolviam-se em um meio cultural de "cunho comunitário", no qual se "articulavam o fazendeiro e os colonos", com possibilidades de organizar a vida das famílias de modo a "explorar mais ou menos o trabalho assalariado, a horta, a criação e o quintal", sempre contando com a força de trabalho da mulher e dos filhos. Mais tarde, com a agroindústria açucareira (em meados do século XX) e o crescimento do mundo urbano, os operários rurais e das usinas vivenciam as relações capitalistas de produção por meio do contrato, envolvendo-se num universo cultural de "cunho societário", não sobrando espaço para a organização da vida diferente das "exigências do ciclo de reprodução do capital". O exemplo disso é o fato de os trabalhadores serem classificados "em residentes e não residentes, permanentes e temporários", além de contar com a contribuição do trabalho doméstico exercido pelas mulheres (Ianni, 2004, p. 92). Assim, como explica Stolcke, a unidade doméstica

deixa de ser unidade de produção e consumo para tornar-se o que Tylly e Scott apropriadamente chamaram de unidade assalariada. E ainda a separação entre casa e local de trabalho, mais perda da relativa autonomia que os colonos tinham para 
organizar o processo de trabalho, dificultaram sobremaneira a integração de relações sociais e de trabalho (Stolcke, 1994, p. 91),

em que pesem as formas de resistências dos trabalhadores e as greves no campo.

Entretanto, ao mesmo tempo em que observamos um movimento de mudanças nas relações de trabalho de uma burguesia comercial tradicional para uma nova burguesia, identificamos permanências.

Outro estudo, desenvolvido por um pesquisador americano (Harris, 1971) no interior da Bahia em 1950, destaca um município com modelo de economia de subsistência pré-capitalista. $\mathrm{O}$ autor descreve várias atividades de trabalho - na área urbana - praticado no espaço doméstico por pequenos produtores, fortemente relacionado à vida familiar, envolvendo o marido, a mulher, filhos, outros membros da família e mais empregados, exercido de modo autônomo, sendo o produto diretamente comercializado com os compradores, assumindo uma forma de trabalho artesanal, como também forma de trabalho remunerado encomendado por terceiros. Em todas as formas de atividade é evidenciada a inserção da mão de obra feminina, mostrando o trabalho remunerado, não remunerado e o não trabalho dividindo o mesmo espaço na vida das famílias. O autor descreve ainda a migração de homens ao deixarem a sua cidade natal para buscar oportunidades de trabalho em São Paulo e ficarem por lá, pelo resto da vida. As mulheres permaneciam no lugar e assumiam diferentes tipos de atividades 'masculinas', como ferreiras, latoeiras etc. Essa realidade desconstrói o princípio que separa a existência de trabalhos de homens e trabalhos de mulheres, legitimados pela ideologia naturalista, o que é comprovado na incorporação das mulheres em diversas funções antes só exercidas pelos homens.

\section{Palavras finais}

O movimento de separação do trabalho produtivo do espaço da reprodução pode ser estudado por meio de reflexões sobre a processualidade histórica na constituição das diferentes formas de família. O exemplo disso é compreendido quando observamos as unidades tradicionais rurais, núcleo da produção familiar, como um lugar hierarquizado entre os sexos, que serve de centro para os relacionamentos sexuais, o cuidado com os filhos, com a casa, no qual as mulheres trabalhadoras, ajudantes dos homens, ocupavam-se diretamente da produção de bens, serviços e da alimentação da família.

Nas sociedades pré-capitalistas e no início do processo de industrialização, o trabalho produtivo e o reprodutivo eram desenvolvidos no mesmo espaço (fato que ainda permanece em regiões do Brasil na forma de agricultura 
familiar), sendo comum o envolvimento de homens e mulheres no exercício das tarefas, uma vez que não havia separação entre esfera privada e esfera pública. Com o crescimento dos centros urbanos e a expansão da sociedade industrial, o trabalho produtivo passou a ser exercido no espaço público, separando-se da vida doméstica. Ou seja, a família perde a sua função de produção e torna-se uma unidade assalariada. Nesse contexto, disseminou-se a ideia de que o lugar da mulher era o lar, ficando sob sua responsabilidade o cuidado dos filhos e do marido - em que pese um grande número de mulheres das classes menos favorecidas integrar a produção social e ser fundamental para os homens o seu trabalho doméstico e extradoméstico.

Vale lembrar de antemão que o movimento entre o 'novo' e o 'velho', entre o 'tradicional' e o 'moderno', não é estático, mas dinâmico, movimentando-se entre uma sociabilidade tradicional, marcada pela economia mercantil simples, e uma 'nova ética do trabalho' capitalista em que as famílias das classes populares deveriam estar aptas a se inserirem no mercado de trabalho assalariado em formação.

O avanço das relações capitalistas dissemina uma ideologia a fim de justificar e reforçar a ordem burguesa, pautada na valorização do trabalho disciplinado, moralizado, que em certa medida, em face das resistências dos trabalhadores, extrapola o chão da fábrica e invade a vida privada das famílias - definindo padrões de conduta em todos os ciclos sociais, construindo especialmente um discurso científico para as mulheres, articulado com o novo modo de vida capitalista, promovendo a criação de uma força de trabalho feminina apta a exercer determinados tipos de ofícios.

Finalmente, as interpretações sobre a divisão sexual do trabalho ao longo deste texto mostraram que as bases históricas trazem explicações a respeito dos fundamentos legitimadores da desigualdade entre os sexos, quando 'desnaturalizam' o que é considerado 'natural'. Mostram como foram construídos os princípios de separação entre homens e mulheres, o que é evidenciado no movimento de separação do lugar do trabalho produtivo na família para a fábrica, decorrente do processo de industrialização.

\section{Notas}

1 Professora do Departamento de Filosofia e Ciências Humanas da Universidade Estadual do Sudoeste da Bahia (UESB), Vitória da Conquista, Bahia, Brasil. Doutora em Educação pela Universidade Federal da Bahia (UFBA). <ana_alves183@hotmail.com>

Correspondência: Universidade Estadual do Sudoeste da Bahia, Departamento de Filosofia e Ciências Humanas, Estrada do Bem-Querer, km 04, CEP 45000-000, Vitória da Conquista, Bahia, Brasil. 
2 Há um debate extenso em torno do trabalho doméstico, principalmente em relação à teoria do valor e à exploração, constituindo um eixo de discussão no campo da economia feminista. Não é objetivo deste texto tratar dessas questões. O tema pode ser estudado em Melo (2009) e Melo e Di Sabatto (2009).

3 Vale ressaltar, conforme Combes e Haicault, que o significado de produção engloba a produção social de bens e a produção social de seres humanos, sendo coisas distintas mas ao mesmo tempo relacionadas. Entretanto, com o objetivo das "exigências de análises levam-nos a atribuir à primeira o nome de produção e à segunda o de reprodução" (Combes e Haicault, 1986, p. 24). Outras explicações sobre a reprodução nos remetem à 'abordagem antroponômica'. No âmbito desta exposição, não iremos nos ater a ela. Os fundamentos dessa abordagem, de acordo com essas autoras, podem ser explorados no livro de Daniel Bertaux (Destinos pessoais e estruturas de classes. São Paulo: Zahar, 1979). Os elementos de análise dessa abordagem buscam compreender "as formas sociais da reprodução nas relações sociais de produção e apreender a sua evolução, em sua articulação com formas de desenvolvimento do capitalismo" (Combes e Haicault, 1986, p. 33).

4 O sentido do que é 'público' remete à ideia do que pode ser visto e ouvido por todos; o 'privado' é o lugar do íntimo. Segundo Matos (2002, p. 38), “A falsa universalidade dos limites entre público e privado fica mais clara se lembrarmos que estes foram mais definidos e precisos a partir da era vitoriana e construídos conjuntamente com a definição das esferas sexuais e da delimitação de espaços para os sexos. O século XIX representa o lar e a família em termos naturais, e a esfera pública, ao contrário, como instância histórica".

5 Essa realidade também fez parte da economia de outros países, a exemplo do trabalho camponês na França. Perrot (2008) recorda o trabalho das camponesas na França nas unidades domésticas, que se funde com o cotidiano da família, com as atividades e os dias da vida rural. Além disso, destaca que esse tipo de atividade perdurou por muito tempo. No período que precede a Segunda Guerra Mundial, era essa a condição de quase metade das mulheres. A autora acrescenta que, no mundo, "as camponesas são certamente ainda maioria, se pensarmos na África, na Ásia e na América Latina” (Perrot, 2008, p. 109-110).

6 Atualmente, muitas mulheres em todo o país ainda realizam atividades no domicílio (informais, terceirizadas) como costureiras ou doceiras, entre outras ocupações.

7 Apesar do avanço do capitalismo e das indústrias mecanizadas, ainda subsistem, na sociedade atual, as unidades tradicionais e modernas de produções (arcaicas e modernas) que se articulam (coexistem) entre si. Por exemplo, as unidades de agricultura familiar, no Brasil, compreendidas como forma social de trabalho e produção, mantêm os traços típicos do campesinato, agrupando todos os membros da família e unindo produção, reprodução e consumo. Nesses espaços, as mulheres sempre desempenham um papel fundamental na produção e na reprodução dirigidas para a subsistência da família, embora persista a invisibilidade do seu trabalho e o fato de não ser remunerado. 


\section{Referências}

ABREU, Alice R. P; SORJ, Bila. (Orgs.). O trabalho invisivel: estudos sobre trabalhadores a domicílio no Brasil. Rio de Janeiro: Rio Fundo, 1993.

CÂNDIDO, Antônio. O caipira e a sua cultura. In: FERNANDES, Florestan (Org.). Comunidade e sociedade no Brasil: leituras básicas de introdução ao estudo macro-sociológico do Brasil. São Paulo: USP, 1972. p. 51-59.

CARDOSO, Ciro F. S. O trabalho na colônia. In: LINHARES, Maria Yedda (Org.). História geral do Brasil. Rio de Janeiro: Campus, 1996. p. 79-99.

CHALHOUB, Sidney. Trabalho, lar \& botequim: o cotidiano dos trabalhadores no Rio de Janeiro da Belle Époque. 2. ed. Campinas: Unicamp, 2001.

COMBES, Danièle; HAICAULT, Monique. Produção e reprodução: relações sociais de sexos e de classes. In: BULPORT-KARTCHEVSY, Andrée et al. O sexo do trabalho. Tradução de Sueli Tomazini Cassal. Rio de Janeiro: Paz e Terra, 1986. p. 23-43.

CORRÊA, Mariza. Repensando a família patriarcal brasileira. In: ARANTES, Antonio. Augusto et al. (Orgs.). Colcha de retalhos: estudos sobre a família no Brasil. 3. ed. Campinas: Editora da Unicamp, 1994. p. 15- 42.

DEL PRIORE, Mary L. M. Brasil Colonial: um caso de famílias no feminino plural. Cadernos de Pesquisa, São Paulo, n. 91, p. 69-75, nov. 1994.

DEVEREUX, Anne-Marie. Família. In: HIRATA, Helena et al. (Orgs.). Dicionário crítico feminino. São Paulo: Editora Unesp, 2009. p. 96-101.

FERNANDES, Florestan. Capitalismo dependente e classes sociais na America Latina. Rio de Janeiro: Zahar Editores, 1973.

FRAGOSO, João Luís. O império escravista e a república dos plantadores. In: LINHARES,
Maria Yedda (Org.). História geral do Brasil. Rio de Janeiro: Campus, 1996. p. 145-195.

FREYRE, Gilberto. Sobrados e mocambos. Rio de Janeiro: J. Olympio, 1961.

Casa grande e senzala. Rio de Janeiro: J. Olympio, 1963.

GALVÃO, Maria de Lourdes S. C. Viagem no tempo, reminiscências. Salvador: Contemp, 1988.

HARRIS, Marvin. Town \& Country in Brazil: a Socio-anthropological Study of a Small Brazilian Town. New York: The Norton Library, 1971.

HIRATA, Helena. Nova divisão sexual do trabalho? Um olhar voltado para a empresa e a sociedade. São Paulo: Boitempo Editorial, 2002.

HOBSBAWM, Eric J. A era dos impérios (18751914). Tradução de S. M. Campos e Y. S. de Toledo. Rio de Janeiro: Paz e Terra, 1988.

A era das revoluções 1789-1848. 16. ed. Tradução de Maria Tereza L. Teixei-ra e Marcos Penchel. Rio de Janeiro: Paz e Terra, 2002.

HUFTON, Olwen. Mulheres, trabalho e família. In: DUBY, Georges; PERROT, Michelle. História das mulheres no Ocidente: do Renascimento à Idade Moderna. Tradução de Alda Maria Durães et al. Porto: Edições Afrontamento, 1991.

IANNI, Octavio. Origens agrárias do Estado brasileiro. São Paulo: Brasiliense, 2004.

KERGOAT, Danièle. Divisão sexual do trabalho e relações sociais de sexo. In: HIRATA, Helena et al. (Orgs.). Dicionário crítico feminino. São Paulo: Editora Unesp, 2009. p. 67-76.

LENIN, Vladimir I. O desenvolvimento do capitalismo na Rússia: o processo de formação do mercado interno para a Grande 
Indústria. In: . Coleção Os Economistas. 2. ed. Tradução de João Paulo Netto. São Paulo: Nova Cultural, 1985.

MATOS, Maria I. Cotidiano e cultura: história, cidade e trabalho. São Paulo: Edusc, 2002.

MATTOSO, Katia M. de Q. A família baiana. In: MATTOSO, Katia M. de Q. Bahia, século XIX: uma província no Império. Rio de Janeiro: Nova Fronteira, 1992. p. 127-220.

MELO, Hildete P. de. Invisibilidade do trabalho feminino: uma violência disfarçada - notas preliminares. In: TORNQYIST, Carmem S. et al. Leituras de resistência: corpo, violência e poder. Florianópolis: Mulheres, 2009. p. 165-184.

MELO, Hildete P. de; Di SABBATO, Alberto. Gênero e trabalho rural 1993/2006. In: BUTTO, Andrea. (Org.). Estatísticas rurais e a economia feminista: um olhar sobre o retrato das mulheres. Ministério do Desenvolvimento Agrário. Gênero, agricultura familiar e reforma agrária no Mercosul. Brasília: MDA/Nead, 2009. p. 31-120. (Nead Debate, 9).

MIRANDA NETTO, Antonio G. et al. Dicionário de ciências sociais. Rio de Janeiro: FGV, 1986.

OPITZ, Claudia. O quotidiano da mulher no final da Idade Média (1250-1500). In: KLAPISCH-ZUBER, C. (Org.). História das mulheres no Ocidente: a Idade Média. Tradução de Ana L. Ramalho et al. Porto: Afrontamento, 1990. p. 353-435.

PERROT, Michelle. Os excluídos da história: operários, mulheres e prisioneiros. Tradução de Denise Bottmann. Rio de Janeiro: Paz e Terra, 1988.

Minha história das mulheres. São Paulo: Contexto, 2008.
PROST, Antoine. Fronteiras e espaços do privado. In: PROST, Antoine; VINCENT, Gérard (Orgs.). História da vida privada 5: da Primeira Guerra a nossos dias. Tradução de Denise Bottmann. São Paulo: Companhia das Letras, 1992. p. 13-152.

RAGO, Margareth. Do cabaré ao lar: a utopia da cidade disciplinar - Brasil 1890-1930. 3. ed. Rio de Janeiro: Paz e Terra, 1997.

SAINT-HILAIRE, August. Segunda viagem do Rio de Janeiro a Minas Gerais e a São Paulo, 1822. Tradução de Vivaldo di Moreira. Belo Horizonte, São Paulo: Itatiaia, USP, 1974.

SAFFIOTI, Heleieth. A mulher na sociedade de classes: mito e realidade. Petrópolis: Vozes, 1979.

SAMARA, Eni de M. As mulheres, o poder, a família. São Paulo: Marco Zero, Secretaria de Estado da Cultura de São Paulo, 1989.

SCOTT, Joan W. A mulher trabalhadora. In: DUBY, Georges; PERROT, Michelle. História das mulheres no Ocidente: o século XIX. Tradução de Claudia Gonçalves e Egito Gonçalves. Porto: Edições Afrontamento, 1991.

SILVEIRA, Ivana. T. Sociedade, educação e família. Aprender: Caderno de Filosofia e Psicologia da Educação, Vitória da Conquista, Bahia, ano IV, n. 7, p. 149-172, 2006.

STOLCKE, Verena. A família que não é sagrada. In: ARANTES, Antonio A. et al. (Orgs.). Colcha de retalhos: estudos sobre a família no Brasil. 3. ed. Campinas: Editora da Unicamp, 1994. p. 61-114.

Recebido em 19/01/2011

Aprovado em 28/02/2013 